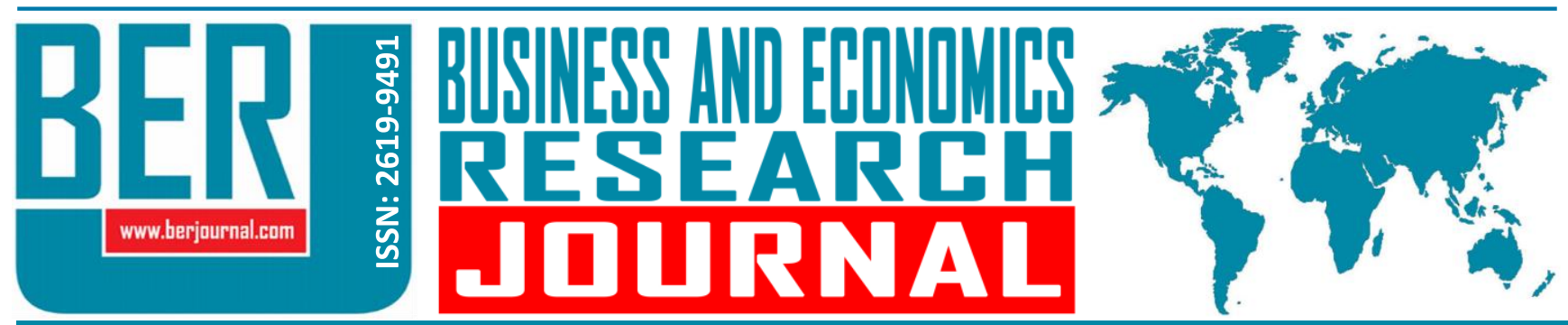

Business and Economics Research Journal Vol. 10, No. 2, 2019, pp. 575-586 doi: 10.20409/berj.2019.186

\section{Süreç Yönetiminin Ürün İnovasyon Performansı Üzerindeki Etkisinde Rekabet Yoğunluğunun Düzenleyici Rolü}

\author{
Bulent Yildiz ${ }^{\mathrm{a}}$, Behzat Sayin ${ }^{\mathrm{b}}$
}

Öz: Tekstil sektöründe yaşanan yoğun rekabet şartları nedeniyle firmaların rekabet güçlerini artırabilmek için süreç yönetimi ve ürün inovasyonuna azami önem vermeleri gerekmektedir. Bu çalışmada süreç yönetiminin ürün inovasyon performansı üzerindeki etkisinde rekabet yoğunluğunun düzenleyici rolü araştırılmıştır. Bu amaçla istanbul'da tekstil sektöründe faaliyet gösteren 124 imalat firmasından anket ile veri toplanmıştır. Veriler yapısal eşitlik modeli ile analiz edilmiştir. Yapılan analizler neticesinde süreç yönetimi ve rekabet yoğunluğunun ürün inovasyon performansını pozitif yönde anlamlı olarak etkilediği bulgusuna ulaşılmıştır. Düzenleyici etki analizi sonucunda ise süreç yönetiminin ürün inovasyon performansı üzerindeki etkisinde rekabet yoğunluğunun düzenleyici etkisi olduğu bulgusu elde edilmiştir.

\section{Moderator Role of Competitive Intensity in the Effect of Process Management on Product Innovation Performance}

Abstract: Due to the intense competition conditions experienced in the textile sector, companies need to give maximum importance to process management and product innovation in order to increase their competitiveness. In this study, the regulatory role of competitive intensity in the impact of process management on product innovation performance was investigated. For this purpose, data were collected from 124 manufacturing companies operating in textile sector in Istanbul. The data were analyzed by structural equation model. As a result of the analyzes, it was found that process management and competition intensity had a positive effect on product innovation performance. As a result of regulatory impact analysis, the effect of competitive intensity on the effect of process management on product innovation performance was obtained.
Anahtar Sözcükler: Süreç Yönetimi, Ürün İnovasyonu, Rekabet Yoğunluğu

JEL: M10, M11

Geliş : 19 Kasım 2018

Düzeltme : 20 Ocak 2019

Kabul : 26 Şubat 2019

Tür : : Araştırma

Keywords: Process Management, Product Innovation, Competitive Density

JEL: M10, M11

Received : 26 Şubat 2019

Revised : 20 January 2019

Accepted : 26 February 2019

Type : Research

Asst. Prof., PhD., Kastamonu University, Kastamonu, Turkiye, yildiz bulent@yahoo.fr (ORCID ID: 0000-0002-5368-2805)

b PhD. Student, Hasan Kalyoncu University, Altunkaya Group of Companies Marketing Chief, Gaziantep, Turkiye, sayinbehzat@hotmail.com (ORCID ID: 0000-0001-9330-1504) 


\section{Giriş}

Günümüzün dinamik ve yoğun rekabet içeren piyasa koşulları gereği işletmeler değişim (change), karmaşıkık (complexity), müşteri talepleri (customer demands), rekabet baskısı (competitive pressure), maliyet etkileri (cost impacts) ve kısıtlamalar (constraints) olarak adlandırılan problemlerle (6C) baş etmek durumundadırlar. Sayılan bu 6 problemin tamamının işletmenin belirtilen iş hedeflerini gerçekleştirme yeteneği üzerinde büyük etkisi vardır. İşletmeler bu problemleri çözmek adına yeni ürün ve hizmetler piyasaya sürmektedir ama çok az işletme bu yeni ürün ve hizmetleri besleyen süreçlerde iyileştirme yapma yolunu tercih etmektedir (Riley, 1999: 6.1).

Dinamik ve yoğun rekabet gerektiren ortamda işletmeler yüksek performans ve rekabet avantajı sağlayacak faaliyetlerde bulunmalıdır. Bununla birlikte işletmelerin, etkili bir şekilde rekabet edebilmeleri için hem verimlilik hem de inovasyon konusunda iyi performans göstermeleri gerekmektedir. Dinamik bir ortamın değişen doğası, işletmelerin inovasyon ve adaptasyon yoluyla rekabet etmesini, aynı zamanda üretkenliği korumasını gerektirir. Birçok işletme bu tür bir rekabet avantajı elde etmek ve bu avantajı sürdürmek için Yalın ve Altı Sigma gibi süreç yönetimi girişimlerine yönelmiştir. Her iki olguda da yüksek performans düzeylerine ulaşmaya çalışmak genellikle süreç yönetimi uygulayan işletmeler için potansiyel bir sorun teşkil etmektedir (Jones ve Linderman, 2014: 335).

Bir iş süreci, insanların, malzemelerin, enerjinin, ekipmanın ve bilginin gerekli bir nihai sonucu (ürün veya hizmet) üretmek için tasarlanan iş faaliyetlerinde mantıksal bir şekilde organize edilmesidir (Riley, 1999: 6.1). Süreç yönetimi ise bahsedilen bu süreçlerin tasarımını, yürürlüğe girmesini, yönetimini ve analizini destekleyen yöntemler, teknikler ve araçları içeren bir paradigma olarak tanımlanmaktadır (Meidan vd., 2017: 71). Süreç yönetimi, sistematik görselleştirme, iş süreçlerinin ölçülmesi ve iyileştirilmesini sunmaktadır (Sujova ve Marcinekova, 2015: 889). Süreç yönetimi; analiz etmek, sürekli üretmek, pazarlama yapmak, iletişimi sağlamak ve şirket için gerekli operasyonları yönetmek gibi temel faaliyetleri geliştirmek amacıyla yapılandırılmış bir yaklaşımdır (Zairi, 1997: 65).

Deming ve Juran gibi uzmanlar süreç yönetiminin evrensel olarak herhangi bir işletme için fayda sağlayacağını iddia etmektedirler. Ancak, süreç yönetiminin verimlilikle ilgili performans ölçümleri üzerindeki etkisi ile ilgili araştırma sonuçları pek net değildir. Bazı araştırmacılar süreç yönetiminin performansı olumlu etkilediğini ileri sürerken, bazıları ise süreç yönetiminin operasyonel performans üzerinde gerçek bir etkisi olmadığını iddia etmektedir (Jones ve Linderman, 2014:336).

Tekstil sektörünün büyümesi, gelişmiş ve esnek süreçler kullanmak suretiyle, ürünlerini, endüstrideki organizasyonel yapıya ve iş uygulamalarına odaklamasına ve sektörde yenilik yapma yeteneğine bağlıdır. Sektör, Çin ve Vietnam gibi ülkelerden rekabetle karşı karşıya kalmıştır ve bununla birlikte, tekstil şirketleri, teknolojik inovasyon süreçlerinde olduğu gibi örgütsel yapılarında, üretim biçimlerinde ve iş organizasyonlarında değişiklikler yapmaya zorlanmaktadır (Padilha ve Gomes, 2016: 285). Rekabetin yoğun olduğu bir sektör olması nedeniyle çalışmanın örneklemini tekstil sektöründe faaliyet gösteren imalat firmaları oluşturmaktadır.

Bu çalışmada süreç yönetimi süreç kontrol, süreç dizaynı ve süreç iyileştirme olmak üzere üç alt başlık altında incelenmiştir.

\section{Kuramsal Çerçeve}

Herhangi bir ürün veya hizmetin istenen nitelikte elde edilebilmesi için kullanılan ve ürünün kalitesini etkileyen makine, ekipman ve işgücü gibi faktörlerin oluşturduğu nedenler sistemine "süreç" adı verilmektedir. Hiç şüphe yoktur ki elde edilen ürünlerin arzu edilen nitelikte olabilmesi için bu sürecin de kontrol altında olması gerekmektedir (Işı̆̆ıçok, 2005: 199).

Geleneksel imalat sistemlerinde, aynı makinenin parçaların üretiminde çalışmasından sorumlu olan operatörün, aynı zamanda prosedürün kontrolünden sorumlu olması yaygın olarak karşılaşılan bir durum değildir. Ancak takım aşınması, makine durumu ve malzeme bileşimi tarafından talep edilen süreçteki gerekli değişiklikleri kontrol altında tutabilmek için operatör ayrıca bir tasarım mühendisinin dikte ettiği boyut ve 
tolerans değişikliklerine de cevap vermelidir. Değişiklikler genellikle, mikrometreler veya diğer türdeki tek amaçlı ölçüm cihazları kullanılarak kalite kontrol tarafından doğrulanmaktadır. Genellikle imalat mühendisinin rehberliği altındaki makine operatörü, artık "hücre" tipi bir işlemdeki birkaç makineden sorumludur ve çoğu zaman istatistiksel kalite kontrolünün (yani kontrol çizelgelerinin) uygulanması ve kullanılmasından da sorumludur (Melton vd., 1997: 87). Süreç kontrolde istatistiğin çok önemli bir rolü bulunmaktadır. Süreç kontrol, süreç kalitesini ölçmek amacıyla yapılır ve sürecin kontrol dışına çıktığı tespit edilirse süreci düzeltmek için gerekli önlemler alınır (Işığıçok, 2005: 37).

Süreç dizaynı üretimde kullanılacak süreçlerin geliştirilmesi, test edilmesi ve standart hale getirilmesini gerekli kılmaktadır. Süreç dizaynı aynı zamanda uygun teknoloji ve makinaların seçimini ve elde edilen sonuçların test edilmesi için pilot üretim faaliyetlerini de içermektedir (Ersoy ve Ersoy, 2015: 128).

Süreç iyileştirme ürün ya da hizmet üreten bir sürecin geliştirilerek daha verimli ve kaliteli üretim yapması için kullanılan sistematik bir yaklaşımdır (Ersoy ve Ersoy, 2015:244). Süreç iyileştirme kabiliyeti, imalat tekniklerini sürekli olarak geliştirme ve performansı işleme kabiliyeti ve istatistiksel süreç kontrolü ve kıyaslama gibi rutinleri içermektedir (Silva vd., 2014: 1317).

Süreç iyileştirme bir işin daha iyi nasıl yapılabileceğine ilişkin bir yolun bulunmasıdır. Süreç iyileştirme problem ve hataların gerçekleşmesi durumunda birini suçlama anlayışını asla benimsememektedir. Aynı zamanda süreç iyileştirme, kriz yönetimi veya sorunlarla boğuşmak yerine işin nasıl daha iyi yapılabileceği ile ilgilenmektedir (Öztürk, 2013: 92-93).

Süreç iyileştirme ve süreç değerlendirmesinin, bir kuruluşun iş hedefleri ve operasyonel hedeflerini uyumlu hale getirme motivasyonunun farkındalığını artırmasına rağmen, bunun nasıl yapılacağı konusunda pratikte çok az bilgi ve deneyim vardır. Ne yazık ki, pratikte bunu başarmak için izlenecek tutarlı bir yöntem ya da rehber bulunmamaktadır. Bu tür bilgilerin eksikliği, başarısız süreç iyileştirme çabalarına yol açabilmektedir (Lepmets vd., 2012: 1448).

Süreç iyileştirmede kullanılan temel araçlar arasında akış şemaları, çetele diyagramı, histogramlar, pareto analizi, serpme diyagramı, seyir ve denetim şemaları, neden sonuç diyagramı gösterilebilir (Ersoy ve Ersoy, 2015).

Freeman (1982)'nin ifade ettiği gibi: İnovasyon, teknik, endüstriyel ve ticari bir dizi operasyonlardır (Tohidi ve Jappari, 2012: 517). Ürün inovasyonu, harici kullanıcıların veya pazarın ihtiyaçlarını karşılamak için sunulan yeni ürünler ve/veya hizmetler olarak tanımlanır (Damanpour, 1991). Ürün inovasyonu, yeni (veya geliştirilmiş) bir ürünün pazarlanmasıyla ilgili teknik tasarım, Ar-Ge, üretim, yönetim ve ticari faaliyetleri kapsayan bir süreçtir (Alegre vd., 2006: 334). Ürün inovasyonu, bir firmanın yeni fikirleri, ürünleri ve süreçleri başarılı ve verimli bir şekilde benimseme yeteneğidir ve firmaların inovasyon kapasitesini başarılı bir şekilde oluşturmalarına yardımcı olabilecek ürün ve süreçlerle ilişkili güncel ve ilgili bilgileri edinme becerisidir (Chang, 2017: 132). Yeni geliştirilen ürünler ve / veya hizmetler için firmanın kârlıı̆ı̆ın, satış hacmini ve gelir hedeflerini ne ölçüde gerçekleştirdiğini göstermesi bakımından ürün inovasyon performansı, ürün yeniliği başarısının önemli bir göstergesidir (Chen vd., 2015: 643). Ürün inovasyonu, firmaların çalkantılı ortamlara uyum sağlamaları ve sürdürülebilir rekabetçi avantaj elde etmelerinin başlıca yoludur (Wu, 2014: 201). Inovasyonun sunduğu faydaları gerçekten elde etmek için, firmalar inovasyonun bir sonuç, bir süreç ve bir zihniyet olduğunu anlamalıdır (Kahn, 2018: 458).

Rekabet, özellikle rekabetin yoğunluğu, stratejik yönetimde önemli bir kavramdır çünkü firma davranışlarını ve performans sonuçlarını etkileyebilir (Wu ve Pangarkar, 2010: 503). Rekabet yoğunluğu, bir firmanın rakipleri tarafından dayatılan, odak firmanın stratejik yanıtını harekete geçirebilecek gerginliğin derecesini belirtir (Wu ve Pangarkar, 2010: 506).

Rekabet yoğunluğu, piyasadaki rakiplerin sayısı ve daha fazla büyüme için potansiyel fırsatların olmaması nedeniyle rekabetin şiddetli olduğu bir durum olarak tanımlanabilir. Rekabet daha da yoğunlaştıkça, bir firmanın davranışının sonuçları artık belirleyici olmayacaktır yani davranışlar rakiplerin üstlendiği eylemler ve beklenmedik durumlardan büyük ölçüde etkilendiği için stokastik olmayacaktır. Bu nedenle, rekabet koşulları altında tahmin edilebilirlik ve kesinlik azalacaktır (Auh ve Menguc, 2005: 1654). 


\section{Araştırma Hipotezlerin Kurulması}

Süreç kontrolü değişkenliği azaltma noktasında önemli katkılar sağlamaktadır. Değişkenliğin azaltılması ise yeni bir gelişim ile ilgili bazı belirsizlikleri azaltarak inovasyona yardımcı olabilir (Jones ve Linderman, 2014: 339). Süreç iyileştirme, bir kuruluşun iş hedeflerine ulaşma yeteneğini geliştirmelidir (Lepmets vd., 2012: 1440). Süreç iyileştirme ve süreç tasarımı da inovasyon performansı üzerinde olumlu etkiye sahiptir. Rekabetçi pazar şartları nedeniyle inovatif firmalar süreçlerinde iyileştirme ve geliştirmeye ihtiyaç duymaktadırlar. Yeni teknoloji ve süreç gerektiren ürünlerde de süreç iyileştime gereklidir. Süreç iyileştirme ve süreç dizaynı uygulamaları, inovasyonu teşvik etmek için ihtiyaç duyulan esnekliği de desteklemektedir. (Jones ve Linderman, 2014: 339-340). Günümüzde işletmeler çalışanlar ve takımlar yetkilendirilmeli ve çalışanlar sorunun nerede ve ne zaman gerçekleştiği konusunda kendi kararlarını verebilmelidir. Bu, insanların günlük deneylerle ürün ve süreçlerde sürekli iyileştirmeleri öğrenebilecekleri ve tanıtabilecekleri bir bağlam yaratmak için gerekli bir önkoşuldur. Yeni ekipman parçaları geliştirmek veya yeni üretim teknolojilerinin benimsenmesini önermek için "aşağıdan yukarıya" fırsatları belirlemek için güçlendirici bir organizasyon da gereklidir (Furlan ve Vinelli, 2018: 170). Yenilikçi olarak süreç iyileştirme yeteneğinin rolüne ilişkin çelişkili argümanlar bulunmaktadır. Süreç iyileştirme, standartlaştırmayı, mevcut rutinleri güçlendirmeyi ve yeniliği engelleyen katılıklar yaratabilecek görev belirsizliğini azaltmayı gerektirir. Bununla birlikte, endüstrilerdeki çoklu vakaların analizi, beklentilerin aksine, süreç standardizasyonunun, teknolojik deneyimi kodlamaya yardımcı olarak ve görev belirsizliğini azaltmak için işbirliğini teşvik ederek inovasyonu teşvik edebileceğini göstermiştir. Sürekli iyileştirme, değişimi teşvik edebilir, yaratıcı düşünmeyi teşvik edebilir ve yeniliği teşvik etmek için korkuyu, kritik unsurları azaltabilir (Silva vd., 2014: 1318).

Bu bağlamda aşağıdaki hipotezler kurulmuştur.

\section{H1: Süreç yönetimi ürün inovasyon performansını pozitif yönde anlamlı olarak etkiler.}

Ürün inovasyon performansı, firmaların süreçlerini ve ürünlerini çevredeki değişikliklere başarı ile adapte etmesinin sonucunda gerçekleştirilebilir (Abu Beker ve Ahmed, 2010). Rekabet yoğunluğu ile inovasyon arasındaki ilişkinin işaretini belirlemenin yanı sıra, araştırmacılar aynı zamanda, doğrusal olmayabilecek ilişkinin şeklini araştırmaya da ilgi gösteriyorlar. Bu ilişkinin alabileceği olası bir şekil, tersine çevrilmiş bir U şekillidir. Pratikte bu, rekabetin düşük olduğu sektörlerde inovasyonun da düşük olacağı anlamına gelecektir. Ancak çok yüksek rekabet seviyeleri olduğunda, inovasyon da düşecektir. Bu teoriyi destekleyecek olan çalışmalar ise sınırlıdır ve eleştiriye açıktır. Dahası, rekabetin sınırlandırılmasından ziyade lider taraftarları, özellikle teknolojik sınırlara yakın sektörlerde inovasyonu teşvik etmek için rekabeti sürdürmenin önemini vurgulamaktadır (Sharpe ve Currine, 2008: 4). Rekabet daha az yoğun olduğunda, firmalar mevcut sistemlerini kullanabilirler. Bununla birlikte, rekabet yoğun olduğunda, firmalar buna göre uyum sağlamalıdır. Firmanın fiyat ve promosyon savaşlarından kurtulmak için hem cesur öğrenim hem de keşif gerektiren risk alma ve proaktif faaliyetlerde bulunması gerekecektir (Auh ve Menguc, 2005:1654). Bu kapsamda aşağıdaki hipotez kurulmuştur.

\section{H2: Rekabet yoğunluğu ürün inovasyon performansını pozitif yönde anlamlı olarak etkiler.}

Düşük rekabet koşullarında, bir firmanın müşteri gereksinimlerine yeterince dikkat etmese bile, performansta önemli bir bozulmaya uğramadığı iddia edilmektedir. Bunun nedeni, müşterilerin alternatiflerin eksikliği nedeniyle firmanın tekliflerine sadık kalmak mecburiyetinde olmasıdır. Tersine, son derece rekabetçi bir pazardaki müşteriler tedarikçilerini değiştirmekte daha özgür oldukları için, bu pazardaki rakiplerinden daha iyi müşteri beklentilerini karşılayan bir firma, performansını önemli ölçüde artıracaktır. Bu, daha az rekabetçi bir pazarda çalışanlarla karşılaştırıldığında, daha rekabetçi bir pazarda faaliyet gösteren firmaların, müşteri gereksinimlerini etkili bir şekilde karşılayabildikleri takdirde, daha yüksek performansa sahip olma olasılığının yüksek olduğunu göstermektedir (Chan vd., 2012: 624).

Bir pazarda rekabet ne kadar yoğunsa müşterilerin alternatifi de o kadar çok olacaktır. Bu nedenle pazarda rekabet eden firmalar müşteri beklentilerine göre hareket etmek zorundadır (Jermias, 2008: 74). Günümüzün tüketici pazarları, daha iyi ürün ve hizmetler için giderek artan bir talep yaşamaktadır. Müşteriler, önceki satın alım fiyatlarından daha az ödeme yaptıklarında bile sürekli olarak iyileştirilmiş kaliteli ürünler ve 
/ veya hizmetler beklemektedir. Bu nedenle, eğer bir şirket rekabetçi olmak isterse, ana amaçlarından biri tutarlı bir şekilde yüksek kalitede ürünler üretmeye odaklanmak olmalıdır (Mason ve Antony, 2000: 233). Yoğun rekabet ortamlarında ürün inovasyonuna gereken önem de verilmelidir. Günümüzde, üretim tesisleri, üretim performansında mükemmeliyet elde etmek, en gelişmiş ekipman ve tesisleri geliştirmek ve ürünlerde ve süreçlerde atılımlar yapmak için inovasyona dayanan küresel bir rekabet avantajı elde etmelidir (Furlan ve Vinelli, 2018: 168). Yenilikçi ürünler rekabet avantajı yaratmada önemli bir rol oynamaktadır ve bir firmanın büyümesine ve kârlılığına önemli ölçüde katkıda bulunabilir (Salomo vd., 2007: 285). Bu doğrultuda aşağıdaki hipotez kurulmuştur.

H3: Süreç yönetiminin ürün inovasyon performansı üzerindeki etkisinde rekabet yoğunluğunun düzenleyici rolü bulunmaktadır.

\section{Araştırmanın Yöntemi}

\subsection{Araştırmanın Modeli}

Araştırmanın modeli Şekil 1'de verilmiştir.

Şekil 1. Araştırma Modeli

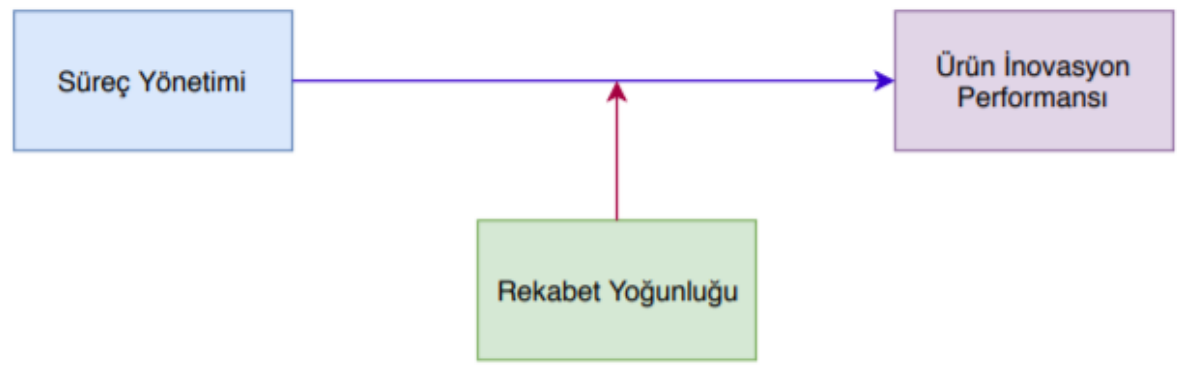

\subsection{Araştırmanın Ölçekleri}

Süreç yönetimi ve rekabet yoğunluğu ölçekleri Sanders ve Linderman (2014) çalışmasından alınmıştır. Süreç yönetimi ölçeği süreç dizaynı, süreç kontrol ve süreç geliştirme olmak üzere üç alt boyuttan oluşmaktadır. Süreç dizaynı boyutu 4 maddeden, süreç kontrol boyutu 5 maddeden, süreç geliştirme boyutu ise 4 maddeden oluşmakta olup ölçek toplam 13 maddeden oluşmaktadır. Sorular katılımcılara $5^{\prime}$ li Likert ölçeğinde sorulmuştur. Katılımcılardan cevaplamalarını "1: Kesinlikle katılmıyorum", "2: Katılmıyorum", "3:Kararsızım", "4: Katılıyorum", "5: Kesinlikle Katılıyorum" şeklinde yapması istenmiştir. Inovasyon performansı ölçeği ise Prajogo ve Sohal'ın (2006) çalışmasından alınmıştır. İnovasyon performansı ölçeği 5 maddeden oluşmaktadır. Sorular katılımcılara 5 'li Likert ölçeğinde sorulmuştur. Katılımcılardan cevaplamalarını "1: Çok az", "2: Az", "3: Eşit”, “4: Fazla”, "5: Çok” fazla şeklinde yapması istenmiştir.

\subsection{Araştırmanın Evren ve Örneklemi}

Araştırmanın evrenini İstanbul Sanayi Odası'na kayıtlı olan ve isstanbul'da tekstil sektöründeki alanlarda (iplik sanayii, örme kumaş sanayii, dokuma kumaş sanayii, ev tekstili, konfeksiyon yan sanayii, deri sanayii, dış ve iç giyim sanayii, triko ve çorap giyim sanayii) faaliyet gösteren 4708 firma oluşturmaktadır. Araştırmanın örneklemini İstanbul'da tekstil sektöründe faaliyet gösteren 124 imalat firması oluşturmaktadır. Araştırmanın örneklemi kolayda örnekleme yöntemi ile belirlenmiştir. Araştırma verileri anket tekniği ile Haziran 2018- Ağustos 2018 arasında toplanmıştır. 


\section{4. Ölçeklerin Yapı Geçerliği ve Güvenilirliği}

Ölçeklerin yapı geçerliği ve güvenilirliğini test etmek amacıyla öncelikle keşfedici faktör analizi (KFA) ve doğrulayıcı faktör analizleri (DFA) yapılmış ardından da güvenilirlik analizi yapıımıştır.

Keşfedici faktör analizi sonucu elde edilen faktör yükleri Tablo 1'de verilmiştir.

Tablo 1. Ölçekler Faktör Yükleri

\begin{tabular}{|c|c|}
\hline Süreç Yönetimi Maddeler & \\
\hline Süreç Dizaynı & Faktör Yükleri \\
\hline Süreçlerimiz etkili bir şekilde geliştirilmekte ve uygulanmaktadır. & 0,839 \\
\hline Yeni süreçler için gerekli organizasyon ve beceri değişikliklerine dikkat ederiz. & 0,759 \\
\hline Müşterilerimizin ihtiyaçlarına cevap verebilmek için son derece gayret gösteriyoruz. & 0,741 \\
\hline Tesisimizdeki süreçler "kusursuz" olacak şekilde tasarlanmıştır. & 0,734 \\
\hline Süreç Kontrol & Faktör Yükleri \\
\hline $\begin{array}{l}\text { Üretim katındaki işlemlerin büyük bir yüzdesi şu anda istatistiksel kalite kontrolü } \\
\text { altındadır. }\end{array}$ & 0,736 \\
\hline $\begin{array}{l}\text { İmalat süreçlerimizin kontrol altında olup olmadığını belirlemek için çizelgeler } \\
\text { kullanıyoruz. }\end{array}$ & 0,613 \\
\hline Süreçlerimizi istatistiksel süreç kontrolünü kullanarak izliyoruz. & 0,601 \\
\hline Makine arızalarının frekansını çizen çizelgeler işyeri tabanına gönderilmektedir. & 0,751 \\
\hline Kalite performansı ile ilgili bilgiler çalışanlar tarafından kolayca elde edilebilir. & 0,856 \\
\hline Süreç Geliştirme & Faktör Yükleri \\
\hline $\begin{array}{l}\text { Statik bir yaklaşım olmadan ürün ve süreçlerin tüm yönlerini sürekli iyileştirmeye } \\
\text { çalışıyoruz. }\end{array}$ & 0,521 \\
\hline $\begin{array}{l}\text { Bir sürecin iyileştirilmesinin hiçbir zaman tamamlanmadığına inanıyoruz; her zaman } \\
\text { daha fazla artan iyileştirme için çaba gösteriyoruz. }\end{array}$ & 0,637 \\
\hline Problem çözme ekipleri, üretim süreçlerinin iyileştirilmesine yardımcı olmaktadır. & 0,800 \\
\hline Üst yönetim, tüm ürün ve süreç iyileştirme önerilerini ciddiye alır. & 0,654 \\
\hline Rekabet Yoğunluğu Maddeler & Faktör Yükleri \\
\hline Oldukça rekabetçi bir sektördeyiz. & 0,691 \\
\hline Rekabet baskılarımız son derece yüksek. & 0,770 \\
\hline Rakiplerimize çok fazla dikkat ediyoruz. & 0,860 \\
\hline $\begin{array}{l}\text { Pazarımızdaki rekabetçi hareketler çok hızlıdır, şirketlerin tepkileri arasında çok kısa } \\
\text { zaman boşlukları vardır. }\end{array}$ & 0,827 \\
\hline Ürün İnovasyon Performansı Maddeler & Faktör Yükleri \\
\hline Firmamızın ürünlerindeki yenilik (değişiklik) düzeyi, sektöre göre... & 0,823 \\
\hline Yeni ürünlerimizde son teknolojilerin kullanım düzeyi, sektöre göre... & 0,828 \\
\hline Yeni ürün geliştirme sürecimizin hızı, sektöre göre... & 0,836 \\
\hline Firmamızın pazara sunduğu yeni ürün sayısı, sektöre göre... & 0,882 \\
\hline Pazarda ilk olan yeni ürün (pazara ilk giren ürün) sayımız, sektöre göre... & 0,831 \\
\hline
\end{tabular}

KFA sonucu proses yönetimi ölçeği için üç boyutlu, rekabetçi yoğunluk ve inovasyon performansı ölçekleri için ise tek boyutlu yapıya ulaşılmıştır. Faktör yükleri süreç yönetimi ölçeği süreç dizaynı boyutu için 0,734 ile 0,839 arasında, süreç kontrol boyutu için 0,601 ile 0,856 arasında, süreç geliştirme boyutu için 0,521 ile 0,800 arasında, rekabetçi yoğunluk ölçeği için 0,691 ile 0,860 arasında, inovasyon performansı ölçeği için ise 0,823 ile 0,886 arasında elde edilmiştir. Proses yönetimi ölçeği için KMO testi neticesinde örneklem yeterlilik değerinin 0,835 olduğu ve örneklem büyüklüğünün faktör analizi için yeterli olduğu bulgusu elde edilmiştir. Ayrıca, Bartlett küresellik testinin anlamlı olması $[\chi 2(78)=725,249, \rho<0,01]$ maddeler arasındaki korelasyon ilişkilerinin faktör analizi için uygun olduğunu göstermektedir. Rekabet yoğunluğu ölçeği için KMO testi neticesinde örneklem yeterlilik değerinin 0,774 olduğu ve örneklem büyüklüğünün faktör analizi için 
yeterli olduğu bulgusu elde edilmiştir. Ayrıca, Bartlett küresellik testinin anlamlı olması $[\chi 2(6)=152,282$, $\rho<0,01]$ maddeler arasındaki korelasyon ilişkilerinin faktör analizi için uygun olduğunu göstermektedir. İnovasyon performansı ölçeği için KMO testi neticesinde örneklem yeterlilik değerinin 0,865 olduğu ve örneklem büyüklüğünün faktör analizi için yeterli olduğu bulgusu elde edilmiştir. Ayrıca, Bartlett küresellik testinin anlamlı olması $[\chi 2(10)=347,769, \rho<0,01]$ maddeler arasındaki korelasyon ilişkilerinin faktör analizi için uygun olduğunu göstermektedir.

KFA sonrası DFA yapılmıştır. DFA sonucu elde edilen uyum iyiliği değerleri Tablo 2'de sunulmuştur.

Tablo 2. DFA Uyum İyiliği Değerleri

\begin{tabular}{|l|c|c|c|c|c|c|c|}
\hline Değişken & $\mathbf{X}^{\mathbf{2}}$ & $\mathbf{d f}$ & $\mathbf{C M I N / d f}$ & $\mathbf{G F I}$ & CFI & TLI & RMSEA \\
\hline Süreç Yönetimi & 98,073 & 57 & 1,721 & 0,897 & 0,940 & 0,917 & 0,077 \\
\hline $\begin{array}{l}\text { Rekabet } \\
\text { Yoğunluğu }\end{array}$ & 0,131 & 2 & 0,066 & 0,999 & 1,000 & 1,000 & 0,000 \\
\hline $\begin{array}{l}\text { Inovasyon } \\
\text { Performansı }\end{array}$ & 2,849 & 4 & 0,712 & 0,991 & 1,000 & 1,000 & 0,000 \\
\hline
\end{tabular}

DFA sonucu ölçeklerin uyum iyiliği değerlerini sağladığı ve iyi uyum gösterdiği görülmektedir (Meydan ve Şeşen, 2015: 37; Gürbüz ve Şahin, 2016: 337).

KFA ve DFA sonrasında ölçekler için güvenilirlik analizi yapılmış ve analiz sonuçları Tablo 3'de verilmiştir.

Tablo 1. Güvenilirlik Analizi

\begin{tabular}{|l|c|c|}
\hline Değişken & Cronbach Alpha Katsayısı & Madde Sayısı \\
\hline Süreç Yönetimi & 0,877 & 13 \\
\hline Süreç Dizaynı & 0,862 & 4 \\
\hline Süreç Kontrol & 0,783 & 5 \\
\hline Süreç Geliştirme & 0,763 & 4 \\
\hline Rekabet Yoğunluğu & 0,798 & 4 \\
\hline İnovasyon Performansı & 0,895 & 5 \\
\hline
\end{tabular}

Güvenilirlik analizi sonucu ölçeklerin güvenilir olduğu bulgusuna ulaşılmıştır (Kalaycı, 2014: 405)

\section{Araştırmanın Bulguları}

Bu kısımda öncelikle araştırmaya katılan firmalara ait bazı demografik bulgular aktarılmıştır. Ardından korelasyon analizine ilişkin bulgular verilmiş ve son olarak da araştırma hipotezlerini test etmek amacı ile yapılan yapısal eşitlik modeli analizi sonuçlarına değinilmiştir.

Firmaların 46'sı 0-15 yıl arası faaliyet göstermekte olup 78'i 16 yıl ve üzeri faaliyette bulunmaktadır. Firmaların 86'sı 0-150 arası çalışana sahip olup, 38'i 151 ve üzeri çalışana sahiptir. Anketi cevaplandıran firma yetkililerinin 48'si firma sahibi/ortağı/genel müdür olarak görev yapmaktadır. 42'si üretim müdürü, 22'si pazarlama müdürü ve $14^{\prime}$ ü ise kalite müdürü olarak görev yapmaktadır. Araştırmaya katılan firma yetkililerinin $58^{\prime} \mathrm{i} 16$ yıl ve üzeri, 66'sı ise $0-15$ yıl arası tecrübeye sahiptir. Firma yetkililerinin $18^{\prime} \mathrm{i}$ lise, $70^{\prime} \mathrm{i}$ üniversite ve 36 'sı lisansüstü düzeyde öğrenime sahiptir. 
Süreç Yönetiminin Ürün İnovasyon Performansı Üzerindeki Etkisinde Rekabet Yoğunluğunun Düzenleyici Rolü

Tablo 4. Korelasyon Analizine İlişkin Bulgular

\begin{tabular}{|l|c|c|c|c|c|}
\hline & Ort. & Std. Sapma & $\begin{array}{c}\text { Inovasyon } \\
\text { Performansı }\end{array}$ & $\begin{array}{c}\text { Rekabet } \\
\text { Yoğunluğu }\end{array}$ & Süreç Yönetimi \\
\hline $\begin{array}{l}\text { İnovasyon } \\
\text { Performansı }\end{array}$ & 3,77 & 0,797 & 1 & & \\
\hline Rekabet Yoğunluğu & 3,83 & 0,732 & $0,424^{* *}$ & 1 & \\
\hline $\begin{array}{l}\text { Süreç } \\
\text { Yönetimi }\end{array}$ & 4,10 & 0,515 & $0,522^{* *}$ & $0,315^{* *}$ & 1 \\
\hline
\end{tabular}

Korelasyon analizi neticesinde rekabet yoğunluğu ve süreç yönetimi ile inovasyon performansı arasında 0,01 anlamlılık düzeyinde aynı yönde orta, rekabet yoğunluğu ile süreç yönetimi arasında 0,01 anlamlılık düzeyinde aynı yönde düşük ilişki olduğu bulgusuna ulaşılmıştır.

Ölçeklerin ortalama değerlerine bakıldığında süreç yönetimi düzeylerinin iyi olduğu, faaliyet gösterdikleri sektörde rekabetin yoğun olduğu, inovasyon performanslarının ise ortalamanın biraz üstünde olduğu bulgusuna ulaşılmaktadır.

Verilerin normal dağılım gösterip göstermediğini test edebilmek için değişkenlerin basıklık ve çarpıklık değerleri ile histogram grafiklerine bakılmıştır. Histogram grafiklerinden verilerin normal dağılıma sahip olduğu bulgusuna ulaşılmıştır. Basıklık ve çarpıklık değerleri Tablo 5 'te verilmiştir.

Tablo 5. Çarpıklık ve Basıklık Değerleri

\begin{tabular}{|l|c|c|}
\hline & Çarpıklık & Basıklık \\
\hline İnovasyon Performansı & $-0,458$ & 0,202 \\
\hline Rekabet Yoğunluğu & $-0,434$ & $-0,225$ \\
\hline Süreç Dizaynı & $-0,738$ & 0,780 \\
\hline Süreç Kontrol & $-0,913$ & 1,681 \\
\hline Süreç Geliştirme & $-0,411$ & $-0,470$ \\
\hline Süreç Yönetimi & $-0,796$ & 0,974 \\
\hline
\end{tabular}

Şekil 2. Yapısal Eşitlik Modeli

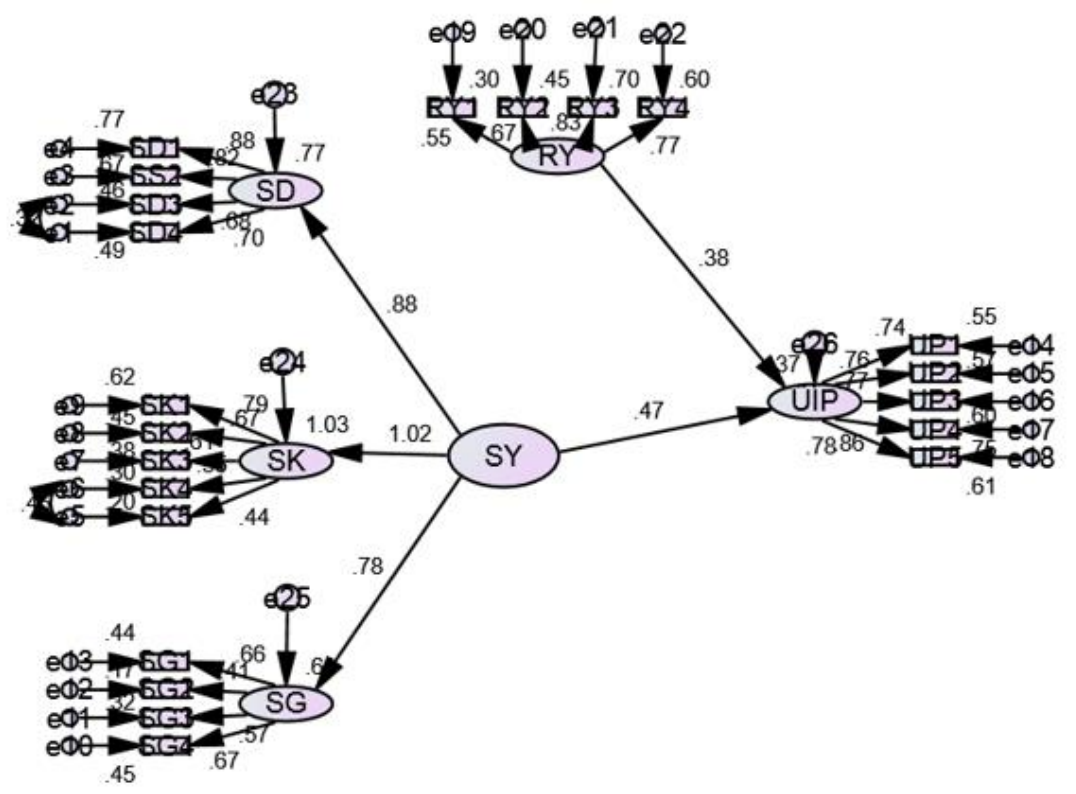


Basıklık ve çarpıklık değerleri -2 ile +2 arasında tespit edildiğinden verilerin normal dağılıma sahip olduğu bulgusu elde edilmiştir (Bayram, 2013: 109; Kalaycı, 2014: 209).

Değişkenler arasındaki etkileşimi analiz edebilmek için öncelikli olarak bir yapısal eşitlik modeli kurulup analiz edilmiştir. Model Şekil 2'de, yapısal model uyum iyiliği değerleri Tablo 6 'da ve yapısal model regresyon ağırlıkları Tablo 7'de sunulmuştur.

Tablo 6. Yapısal Eşitlik Modeli Uyum İyiliği Değerleri

\begin{tabular}{|l|c|c|c|c|c|c|c|}
\hline & $\mathbf{X}^{\mathbf{2}}$ & df & CMIN/df & CFI & GFI & TLI & RMSEA \\
\hline $\begin{array}{l}\text { Yapısal Eşitlik } \\
\text { Modeli }\end{array}$ & 308,421 & 199 & 1,55 & 0,915 & 0,823 & 0,901 & 0,067 \\
\hline
\end{tabular}

Yapısal eşitlik modeli kabul edilebilir uyum iyiliği değerlerini sağlamakta ve iyi uyum göstermektedir (Meydan ve Şeşen, 2015: 37; Gürbüz ve Şahin, 2016: 337)

Tablo 7. Yapısal Eşitlik Modelleri Regresyon Ağırlıkları

\begin{tabular}{|l|l|l|c|c|c|c|c|}
\hline \multicolumn{2}{|c|}{ Test Edilen Yol } & B & $\beta$ & $\begin{array}{c}\text { Std. } \\
\text { Hata }\end{array}$ & $\begin{array}{c}\text { Kritik } \\
\text { Oran }\end{array}$ & Anlamlılık \\
\hline $\begin{array}{l}\text { Ürün İnovasyon } \\
\text { Performansı }\end{array}$ & $<---$ & Süreç Yönetimi & 0,731 & 0,472 & 0,172 & 4,248 & $* * *$ \\
\hline $\begin{array}{l}\text { Ürün İnovasyon } \\
\text { Performansı }\end{array}$ & $<---$ & $\begin{array}{l}\text { Rekabet } \\
\text { Yoğunluğu }\end{array}$ & 0,566 & 0,381 & 0,167 & 3,390 & $* * *$ \\
\hline
\end{tabular}

Tablo 7'de B standardize edilmemiş ve $\beta$ ise standardize edilmiş katsayı tahmin değerini göstermektedir. Yapısal eşitlik modelinin analizi neticesinde süreç yönetimi ve rekabet yoğunluğunun ürün inovasyon performansını pozitif yönde anlamlı olarak etkilediği bulgusuna ulaşılmıştır. Süreç yönetiminin ürün inovasyon performansı üzerindeki etkisinde standartize edilmiş katsayı tahmin değeri 0,472 olarak elde edilmiştir. Bu bulgu ürün inovasyon performansının \%47,2'sinin süreç yönetimi tarafından açıklandığını göstermektedir. Rekabet yoğunluğunun ürün inovasyon performansı üzerindeki etkisinde standardize edilmiş katsayı tahmin değeri 0,381 olarak elde edilmiştir. Bu bulgu ürün inovasyon performansının \%38,1'inin rekabet yoğunluğu tarafından açıklandığını göstermektedir.

Süreç yönetiminin ürün inovasyon performansı üzerindeki etkisinde rekabet yoğunluğunun düzenleyici rolünü analiz edebilmek için öncelikle süreç yönetimi değişkeni ile rekabet yoğunluğu değişkeninin çarpımından oluşan bir etkileşim değişkeni oluşturulmuştur. Ardından regresyon analizi ile etki analiz edilmiştir. Analiz sonuçları Tablo 8'de sunulmuştur.

Tablo 2. Rekabet Yoğunluğu Düzenleyici Etki Analizi

\begin{tabular}{|l|c|c|c|c|c|}
\hline & B & Std. Hata & Beta & t & Anlamlılık \\
\hline Sabit Terim & $-0,047$ & 0,064 & & $-0,744$ & 0,458 \\
\hline $\begin{array}{l}\text { Rekabet } \\
\text { Yoğunluğu }\end{array}$ & 0,283 & 0,082 & 0,265 & 3,456 & 0,001 \\
\hline $\begin{array}{l}\text { Süreç } \\
\text { Yönetimi }\end{array}$ & 0,552 & 0,099 & 0,424 & 5,576 & 0,000 \\
\hline Etkileşim & 0,298 & 0,130 & 0,168 & 2,301 & 0,023 \\
\hline
\end{tabular}

Bağımlı Değişken: Ürün İnovasyon Performansı 
Düzenleyici etki analizi neticesinde rekabet yoğunluğu ve süreç yönetiminin ürün inovasyon performansını pozitif yönde anlamlı olarak etkilediği bulgusuna ulaşılmıştır. Ayrıca rekabet yoğunluğu ve süreç yönetimi değişkenlerinin çarpımından oluşan etkileşim değişkeninin de ürün inovasyon performansını anlamlı olarak etkilediği bulgusu elde edilmiştir. Bu bulgu süreç yönetiminin ürün inovasyon performansı üzerindeki etkisinde rekabet yoğunluğunun düzenleyici rolü bulunduğunu göstermektedir. Ayrıca analiz neticesinde düzeltilmiş $R^{2}$ değeri 0,375 ve Durbin-Watson değeri ise 1,654 olarak elde edilmiştir. $R^{2}$ değeri 0,375 ürün inovasyon performansındaki değişimlerin $\% 37,5^{\prime}$ inin rekabet yoğunluğu ve süreç yönetimi tarafından açıklandığını göstermektedir.

Düşük ve yüksek rekabetçi yoğunluk ilişkisinin düzenleyici etkisini gösteren grafik Şekil 3’te sunulmuştur. Grafiği oluşturabilmek için standardize edilmemiş beta katsayısı tahmin değerleri kullanılmıştır. Grafik hazırlanırken Jerammy Dawson'ın http://www.jeremydawson.co.uk/slopes.htm adresinde hazırlamış olduğu Excel tablodan faydalanılmıştır.

Şekil 3. Düşük ve Yüksek Rekabetçi Yoğunluk illişkisi Düzenleyici Etkisi

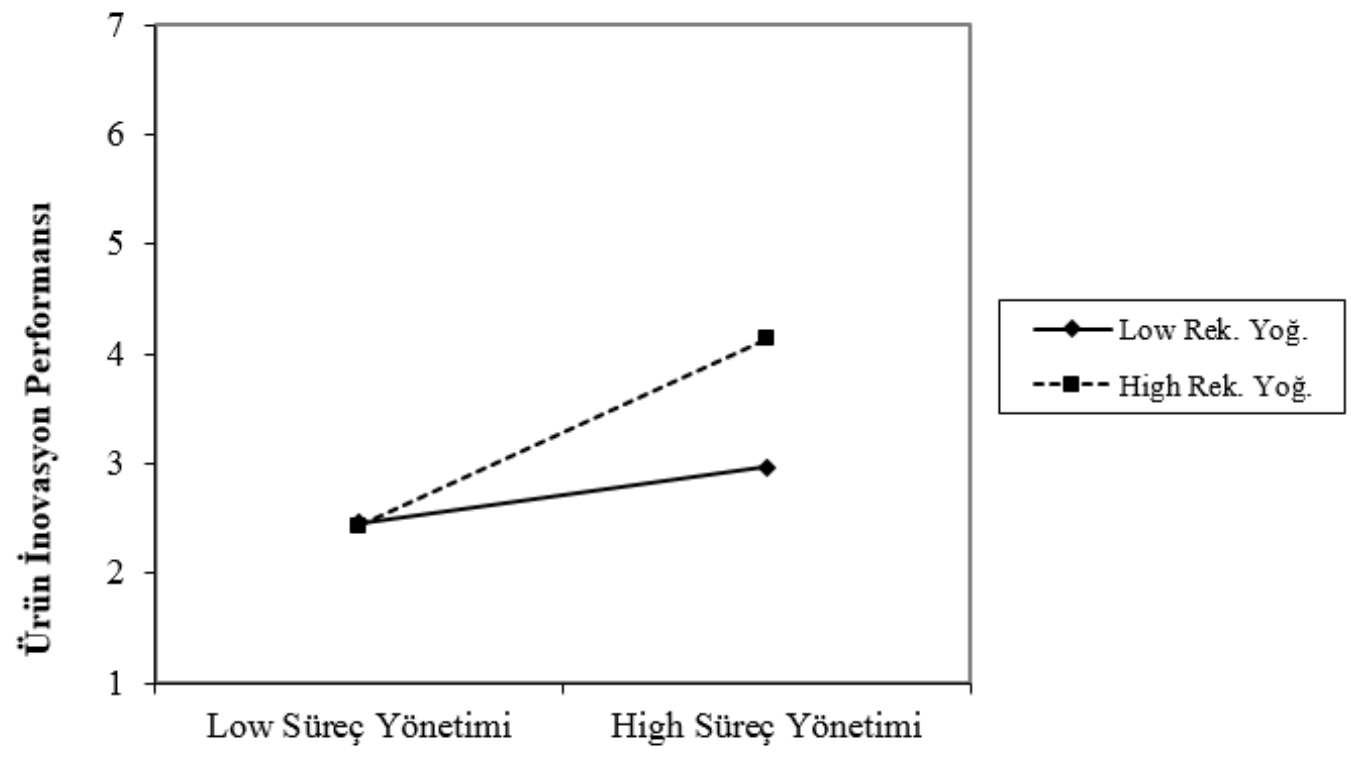

Şekil 3 incelendiğinde tekstil sektöründe faaliyet gösteren imalat firmalarının rekabet yoğunlukları arttığında inovasyon performanslarında da bir artış meydana geldiği, aynı şekilde yüksek rekabetçi yoğunluk durumunda süreç yönetiminde de bir artış meydana geldiği görülmektedir. Grafikte kesikli çizgiler yüksek rekabet yoğunluğunu göstermektedir. Düşük rekabet yoğunluğunda ise inovasyon performansında da bir düşüş meydana geldiği gözlemlenmektedir.

\section{Sonuç}

Bu çalışmada tekstil sektöründe faaliyet gösteren imalat firmalarından anket yöntemi ile elde edilen veriler ile süreç yönetiminin ürün inovasyon performansı üzerindeki etkisinde rekabet yoğunluğunun düzenleyici rolü araştırılmıştır. Araştırma kapsamında öncelikle araştırmada kullanılan ölçeklerin yapı geçerliği ve güvenilirliği test edilmiştir. Bu amaçla keşfedici ve doğrulayıcı faktör analizleri ile güvenilirlik analizi yapılmıştır. Araştırma hipotezleri öncelikli olarak kurulan yapısal eşitlik modeli ile test edilmiştir. Yapısal eşitlik modelinin analizi neticesinde süreç yönetimi ve rekabet yoğunluğunun ürün inovasyon performansını pozitif yönde anlamlı olarak etkilediği bulgusuna ulaşılmıştır. Rekabet yoğunluğunun düzenleyici etkisi regresyon analizi ile test edilmiştir. Analiz sonucu süreç yönetiminin ürün inovasyon performansı üzerindeki etkisinde rekabet yoğunluğunun düzenleyici rolü olduğu tespit edilmiştir. Elde edilen bulguların literatüre önemli katkı sağlayacağına inanılmaktadır. Analiz sonuçları Sanders ve Linderman (2014) çalışmasının sonuçları ile benzerlik göstermektedir. 
Tekstil sektörü ülkemizde ciddi rekabet koşulları altında çalışmaktadır. Tekstil sektöründe faaliyet gösteren firmalar hem kendi aralarında rekabeti yaşarken hem de özellikle Çin ile rekabet edebilmek için önemli çabalar harcamaktadır. Rekabet edebilirlikte kaliteli üretim ve maliyetleri düşürme yanında ürünlerde yapılacak yenilik düzeyleri ve yeni ürün geliştirme faaliyetleri de önemli bir yere sahiptir. Bunu gerçekleştirmek için firmaların ürünlerin üretimini gerçekleştirdikleri süreçlerinin yönetimine de gerekli önemi vermeleri gerekmektedir. Süreç kontrolü sayesinde ürün yenilikleri ile ilgili süreci etkin olarak yönetebileceklerdir. Süreç dizaynı ve süreç iyileştirme sayesinde yeni ürün geliştirme faaliyetleri için süreçlerde gerekli olacak değişikliklerin etkin yönetimini sağlayabileceklerdir. Tekstil sektöründe müşterilerin sürekli olarak yeni tasarımlar talep etmesi ve farklı markalardaki ürünleri internetten rahatlıkla takip edebilmesi ve karşılaştırma yapabilmesi nedenleriyle sektörde inovasyon çok önemli bir yere sahiptir. Günümüzde tüketiciler farklı kıyafetler giymeyi ya da evlerinde kullandıkları tekstil ürünlerinin farklı olmasını da talep etmektedir. Bu da tekstil sektöründe hızlı değişime neden olmaktadır. Bu değişime ayak uydurabilmek için ürün inovasyonu sürekli olarak canlı tutulmak zorundadır. Ürün inovasyonu ile rekabet edebilmek için ise üretim sürecinin sürekli kontrol altında tutulması, sürecin inovasyon faaliyetlerine uyacak şekilde düzenli olarak dizayn edilmesi ve sürecin sürekli olarak iyileştirilmesi elzem olmaktadır.

$\mathrm{Bu}$ araştırmanın en önemli kısıtı sadece İstanbul'da faaliyet gösteren tekstil firmaları üzerinde yapılmış olmasıdır. Bu nedenle farklı sektörlerde de yapılan çalışmalarda araştırma sonuçları farklıık gösterebilecektir. Ayrıca araştırma anket ile toplanan veriler üzerinden yapıımıştır. Bu nedenle ankete verilen cevapların doğru olduğu varsayılmıştır.

Bu çalışma rekabetin çok yoğun olduğu düşünülen tekstil sektöründe yapılımıştır. Diğer sektörlerde de yapılması ve sonuçların karşılaştırılması literatüre katkı açısından önem arz etmektedir. Ayrıca çalışmada bağımlı değişken ürün inovasyon performansıdır. Süreç yönetiminin ürün kalitesi ve/veya kalite performansı üzerindeki etkisinin de incelenmesi önemli olacaktır.

\section{Kaynaklar}

Abu Baker, L., \& Ahmad, H. (2010). Assessing the relationship between firm resources and product innovation performance: A resource-based view. Business Process Management Journal, 16(3), 420-435.

Alegre, J., Lapiedra, R., \& Chiva, R. (2006). A measurement scale for product innovation performance. European Journal of Innovation Management, 9(4), 333-346.

Auh, S., \& Menguc, B. (2005). Balancing exploration and exploitation: The moderating role of competitive intensity. Journal of Business Research, 58, 1652-1661.

Bayram, N. (2013). Yapısal eşitlik modellemesine giriş Amos uygulamaları (2. Baskı). Bursa: Ezgi Kitabevi.

Chan, R. Y. K., He, H., Hing Kai, C., \& Wang, W. Y. C. (2012). Environmental orientation and corporate performance: The mediation mechanism of green supply chain management and moderating effect of competitive intensity. Industrial Marketing Management, 41, 621-630.

Chang, J. (2017). The effects of buyer-supplier's collaboration on knowledge and product innovation. Industrial Marketing Management, 65, 129-143.

Chen, Y., Wang, Y., Nevo, S., Benitez-Amado, J., \& Kou, G. (2015). IT capabilities and product innovation performance: The roles of corporate entrepreneurship and competitive intensity. Information \& Management, 52, 643-657.

Damanpour, F. (1991). Organizational innovation: A meta-analysis of effects of determinants and moderators. The Academy of Management Journal, 34(3), 555-590.

Ersoy, M. S., \& Ersoy, A. (2015). Kalite yönetimi toplam kalite yönetimi ve kalite denetimi (2. Baskı). Ankara: İmaj Yayınevi.

Furlan, A., \& Vinelli, A. (2018). Unpacking the coexistence between improvement and innovation in world-class manufacturing: A dynamic capability approach. Technological Forecasting \& Social Change, 133, 168-178.

Gürbüz, S., \& Şahin, F. (2016). Sosyal bilimlerde araştırma yöntemleri felsefe, yöntem, analiz (3. Baskı). Ankara: Seçkin Yayıncilik.

Jermias, J. (2008). The relative influence of competitive intensity and business strategy on the relationship between financial leverage and performance. The British Accounting Review, 40, 71-86. 
Jones, J. L. S., \& Linderman, K. (2014). Process management, innovation and efficiency performance: The moderating effect of competitive intensity. Business Process Management Journal, 20(2), 335-358.

Işığıçok, E. (2005). Toplam kalite yönetimi bakış açısıyla istatistiksel kalite kontrol (1. Baskı). Bursa: Ezgi Kitabevi.

Kahn, K. B. (2018). Understanding innovation. Business Horizons, 61, 453-460.

Kalaycı, Ş. (2014). SPSS uygulamalı çok değişkenli istatistik teknikleri (6. Baskı). Ankara: Asil Yayın Dağıtım.

Lepmets, M., McBride T., \& Rasa, E. (2012). Goal alignment in process improvement. The Journal of Systems and Software, 85, 1440-1452.

Mason, B., \& Antony, J. (2000). Statistical process control: An essential ingredient for improving service and manufacturing quality. Managing Service Quality: An International Journal, 10(4), 233-238.

Meidan, A., García-García, J. A., Escalona, M. J., \& Ramos, I. (2017). A survey on business processes management suites. Computer Standards \& Interfaces, 51, 71-86.

Melton, K. D., English, J. R., \& Taylor, D. (1997). A statistical process control approach to process diagnosis in discrete manufacturing environments. International Journal of Quality Science, 2(2), 234-259.

Meydan, C. H., \& Şeşen, H. (2015). Yapısal eşitlik modellemesi Amos uygulamaları (2. Baskı). Ankara: Detay Yayıncılık.

Öztürk, A. (2013). Kalite yönetimi ve planlaması (2. Baskı). Bursa: Ekin Yayıncılık.

Padilha, C. K., \& Gomes, G. (2016). Innovation culture and performance in innovation of products and processes: A study in companies of textile industry. RAI Revista de Administração e Inovação, 13, 285-294.

Prajogo, D. I., \& Sohal, A. S. (2006). The integration of TQM and technology/R\&D management in determining quality and innovation performance. Omega, 34(3), 296-312.

Riley, J. F. (1999). Process Management. (Ed.) J. M. Juran ve A. B. Godfrey, Juran's quality handbook (5th ed., pp. 6.16.21). New York: McGraw Hill.

Salomo, S., Joachim, W., \& Gemuenden, H. G. (2007). NPD planning activities and innovation performance: The mediating role of process management and the moderating effect of product innovativeness. Journal of Product Innovation Management, 24(4), 285-302.

Sanders, J. L., \& Linderman, J. K. (2014). Process management, innovation and efficiency performance: The moderating effect of competitive intensity. Business Process Management Journal, 20(2), 335-358.

Sharpe, A., \& Currine, L. (2008). Competitive intensity as driver of innovation and productivity growth: A synthesis of the literature. CSLS Research Report No. 2008-3.

Silva, G. M., Gomes, P. J., Lages L. F., \& Pereira, Z. L., (2014). The role of TQM in strategic product innovation: An empirical assessment. International Journal of Operations \& Production Management, 34(10), 1307-1337.

Sujova, A., \& Marcinekova, K. (2015). Modern methods of process management used in Slovak enterprises. Procedia Economics and Finance, 23, 889-893.

Tohidi, H., \& Jappari, M. M. (2012). Technologic innovation process improvement. Procedia Technology, 1(2012), 517520.

Wu, J., \& Pangarkar, N. (2010). The bidirectional relationship between competitive intensity and collaboration: Evidence from China. Asia Pacific Journal of Management, 27(3), 503-522.

$\mathrm{Wu}, \mathrm{J}$. (2014). Cooperation with competitors and product innovation: Moderating effects of technological capability and alliances with universities. Industrial Marketing Management, 43, 199-209.

Zairi, M. (1997). Business process management: A boundaryless approach to modern competitiveness. Business Process Management Journal, 3(1), 64-80. 